\title{
Efficacy of Herbicide Active Ingredients Against Aquatic Weeds ${ }^{1}$
}

\section{K. Langeland, M. Netherland, W. Haller, and T. Koschnick ${ }^{2}$}

Only those herbicide products that are registered for application directly to water by the United States Environmental Protection Agency and the Florida Department of Agriculture and Consumer Services (FDACS) may be used in Florida to control weeds growing in water. Active ingredients that are contained in aquatic herbicide products may also be present in products that are not approved for aquatic uses. It is not legal to apply a herbicide directly to water unless the herbicide label has specific instructions for application to water. Instructions for aquatic use may restrict the use of water (for a given period of time) for irrigation and mixing agricultural sprays, domestic use, recreational use, watering livestock, or consuming fish from treated water. It is legal to use a herbicide for attempting to control a plant species that is not listed on the label as long as the product is labeled for the site. A permit from the Florida Department of Environmental Protection is required for control of weeds in public waters and waters with multiple ownership.
Table 1 is intended to provide a quick reference to the effectiveness of herbicide active ingredients for controlling common aquatic weeds. Sensitivity of the target weed to the active ingredient is only one consideration in choosing the appropriate herbicide product. Other factors that may be important include water uses, other plant species present, toxicity to fish and other organisms, and additives in individual products. These considerations, as well as other important aspects of aquatic weed control, are discussed more fully in other publications such as "Aquatic Pest Control Applicator Training Manual" and "Weed Control in Ponds". Both of these publications are available from the IFAS Extension Book Store (800/226-1764, http://IFASbooks.ufl.edu). "Weed Control in Florida Ponds" can be viewed or printed from the IFAS Extension Data Information Source (http://edis.ifas.ufl.edu/AA238). Specific product information should be obtained by consulting the product labels and label instructions must be followed for a legal application.

1. This document is SS-AGR-44, one of a series of the Agronomy Department, Florida Cooperative Extension Service, Institute of Food and Agricultural Sciences, University of Florida. Original publication date September 2006. Visit the EDIS Web Site at http://edis.ifas.ufl.edu.

2. Ken Langeland, professor, Agronomy Department, Center for Aquatic and Invasive Plants; Michael Netherland, courtesy associate professor, Center for Aquatic and Invasive Plants; William Haller, professor, Center for Aquatic and Invasive Plants; Tyler Koschnick, research assistant professor, Agronomy Department; Florida Cooperative Extension Service, Institute of Food and Agricultural Sciences, University of Florida, Gainesville, FL 32611.

The use of trade names in this publication is solely for the purpose of providing specific information. UF/IFAS does not guarantee or warranty the products named, and references to them in this publication does not signify our approval to the exclusion of other products of suitable composition. Use herbicides safely. Read and follow directions on the manufacturer's label. 
Anyone who applies herbicides commercially or for a public agency should be licensed as a Restricted Use Pesticide (RUP) applicator. Information pertaining to RUP applicator training and licensing can be obtained from your County Cooperative Extension Service office. It is recommended that private pond owners employ a reputable aquatic plant management company to maintain their ponds. Individuals who choose to apply herbicides to their own ponds should attain a basic understanding of herbicide application and ecology through RUP certification training.

Some herbicide active ingredients are available in only one or a limited number of products, which are registered for aquatic use, while others are available in many different products. Some of these products are identical, while others may differ in additives that can affect the performance of the active ingredient. Representatives for herbicide manufacturers and distributors can provide information on different products. FDACS, Division of Agricultural Environmental Services (850/847-2130) maintains a list, with reference to the active ingredients they contain, of all pesticide products registered in Florida (http://flpesticide.us). Specimen product labels can be obtained from the Crop Data Management Systems, Inc (http://www.cdms.net/manuf/manuf.asp) or from manufacturer representatives or their Web sites. 


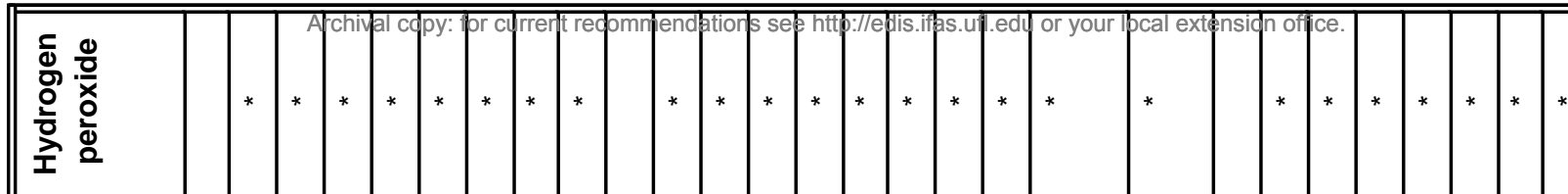

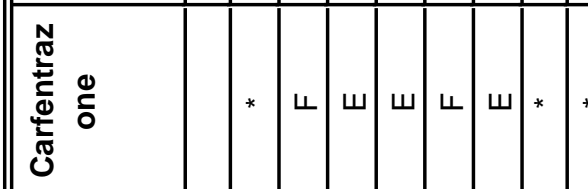

$\frac{1}{2}$

ऽ * ५

ш *

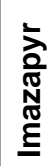

ш

ऽ

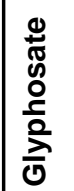

** * * *

ऽ

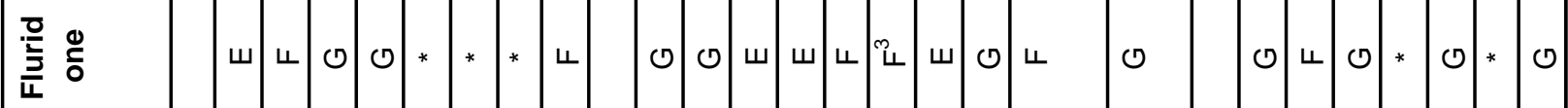

ㅎํㅇ

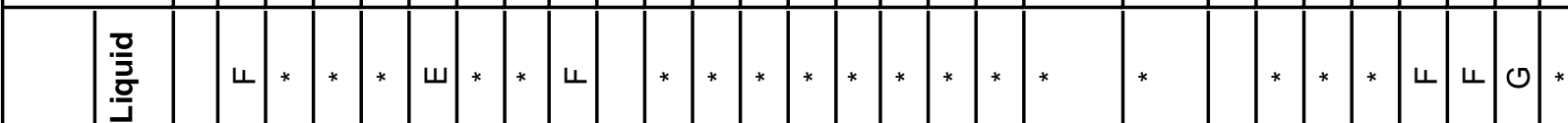

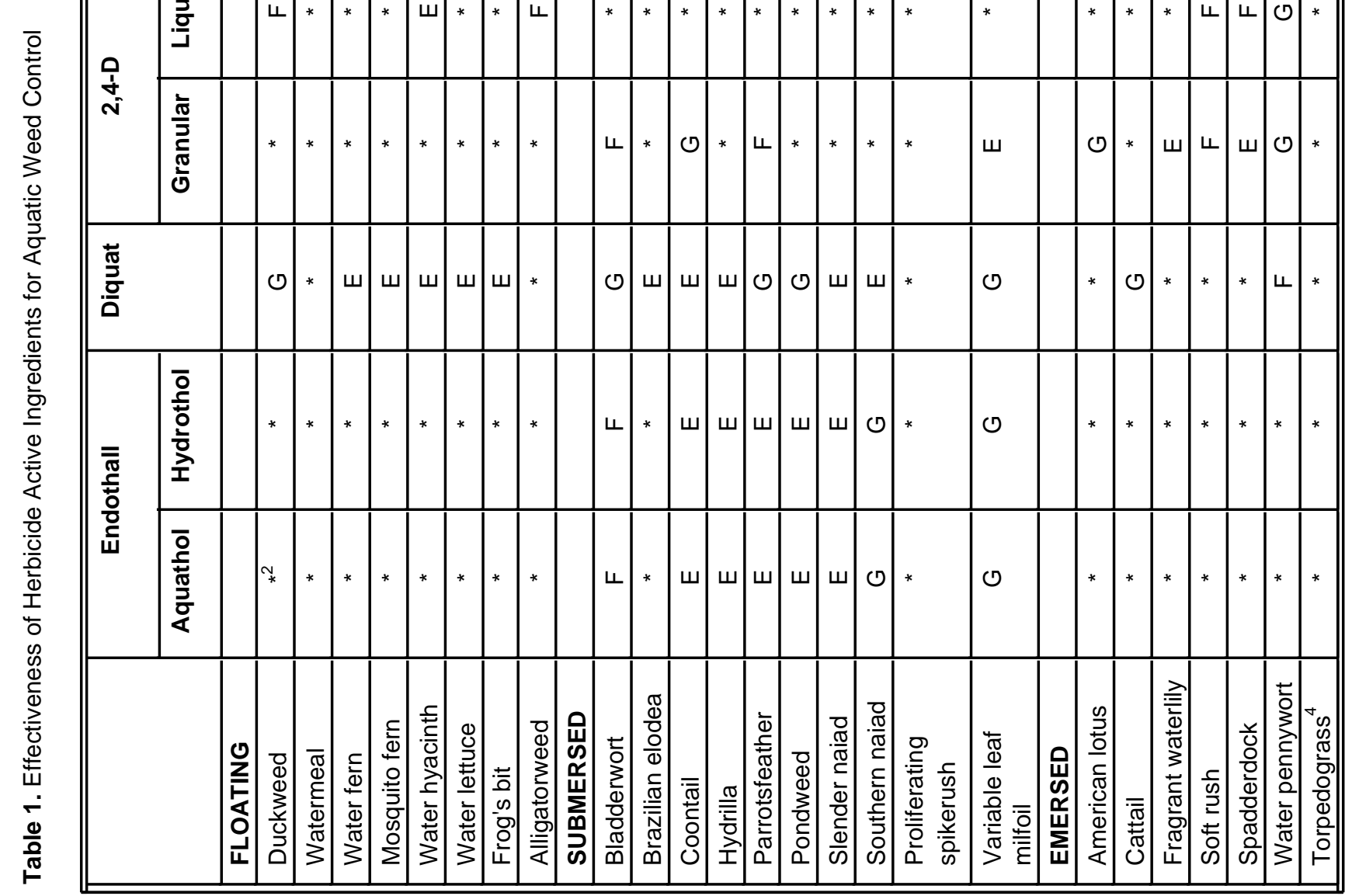




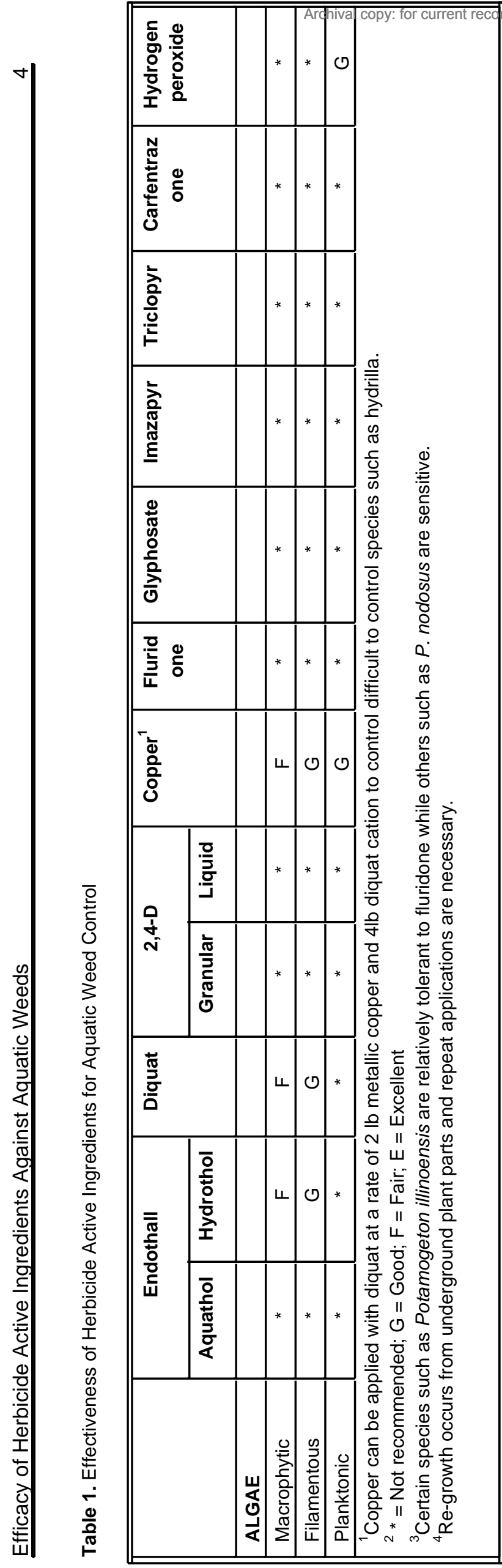

